\title{
Efeitos da suplementação crônica da creatina sobre a função renal: revisão da
}

\section{literatura}

\author{
Effects of chronic creatine supplementation on kidney function: a review \\ Efectos de la suplementación crónica con creatina sobre la función renal: revisión de la literatura
}

Recebido: 16/10/2021 | Revisado: 23/10/2021 | Aceito: 24/10/2021 | Publicado: 26/10/2021

\author{
Alvaro Emilio Baldin \\ ORCID: https://orcid.org/0000-0002-9477-5995 \\ Centro Universitário da Fundação Assis Gurgacz, Brasil \\ E-mail: aebaldin@minha.fag.edu.br \\ Ellen Carolina Zawoski Gomes \\ ORCID: https://orcid.org/0000-0002-0543-6642 \\ Centro Universitário da Fundação Assis Gurgacz, Brasil \\ E-mail: carolinazawoski@fag.edu.br \\ Suzana Bender \\ ORCID: https://orcid.org/0000-0001-8913-1952 \\ Centro Universitário da Fundação Assis Gurgacz, Brasil \\ E-mail: suzanabender@fag.edu.br \\ Vagner Fagnani Linartevichi \\ ORCID: https://orcid.org/0000-0002-2624-7744 \\ Centro Universitário da Fundação Assis Gurgacz, Brasil \\ E-mail: linartevichi@fag.edu.br
}

\begin{abstract}
Resumo
Introdução: a suplementação da creatina tem sido amplamente utilizada para melhorar o desempenho atlético. Além disso, descobertas recentes indicam que este suplemento tem um importante efeito terapêutico em muitas doenças caracterizadas por atrofia, fraqueza muscular e doenças metabólicas (músculos, ossos, pulmão e cérebro). Objetivo: analisar por meio de uma revisão da literatura os efeitos do uso crônico da creatina sobre a função renal. Metodologia: trata-se de uma revisão argumentativa da literatura, de base técnica quantitativa descritivo-exploratória. As amostras pesquisadas foram advindas de periódicos, nacionais e internacionais, publicados entre os anos de 2011 e 2021 . Os periódicos foram adquiridos dos bancos de dados eletrônicos Scielo e PubMed. Resultados: Diversos estudos, a maioria realizado em homenss realizando treinamento resistido três vezes por semana foram suplementados com monohidrato de creatina em diferentes concentrações, por 7 dias e comparados com controles pareados suplementados com dextrosol. Vários testes foram realizados, em alguns deles, amostras de sangue e urina foram coletadas antes e 30 dias após a suplementação no qual inúmeros parâmetros bioquímicos e função renal foram avaliados. A suplementação de creatina monohidratada não causou eventos adversos e, como esperado, promoveu aumento do desempenho e do peso corporal. Conclusões: o presente estudo não encontrou na literatura, evidências que sustentem que a creatina pode representar um risco para a saúde de homens saudáveis. No entanto, casos na literatura sugerem que a creatina pode prejudicar a função renal com o uso indiscriminado, para não trazer riscos à saúde, recomenda-se que indivíduos saudáveis que fazem uso regular desse suplemento não ultrapassem $5 \mathrm{~g} /$ dia.
\end{abstract}

Palavras-chave: Creatina; Aumento do músculo esquelético; Suplementação alimentar.

\begin{abstract}
Introduction: Creatine supplementation has been widely used to improve athletic performance. Furthermore, recent discoveries indicate that this supplement has an important therapeutic effect in many diseases characterized by atrophy, muscle weakness and metabolic diseases (muscle, bone, lung and brain). Aim: to analyze through a literature review the effects of chronic use of creatine on kidney function. Methodology: this is an argumentative literature review, based on quantitative descriptive-exploratory technique. The researched samples came from national and international journals, published between the years 2011 and 2021. The journals were acquired from the Scielo and PubMed electronic databases. Results: Several studies, mostly executed on men performing resistance training three times a week, were supplemented with creatine monohydrate at different dosis for 7 days and compared with matched controls supplemented with dextrosol. Several tests were performed, in some of them, blood and urine samples were collected before and 30 days after supplementation in which numerous biochemical parameters and renal function were evaluated. Creatine monohydrate supplementation did not produce adverse events and, as expected, promoted an increase in performance and body weight. Conclusions: the present paper did not find evidence in the literature to
\end{abstract}


support that creatine may represent a risk to the health of healthy men. However, cases in the literature suggest that creatine can harm kidney function with indiscriminate use, so as not to bring health risks, it is recommended that healthy individuals who regularly use this supplement do not exceed $5 \mathrm{~g} /$ day.

Keywords: Creatine; Skeletal muscle enlargement; Supplementary feeding.

\section{Resumen}

Introducción: la suplementación con creatina se ha utilizado ampliamente para mejorar el rendimiento deportivo. Además, descubrimientos recientes indican que este suplemento tiene un importante efecto terapéutico en muchas enfermedades caracterizadas por atrofia, debilidad muscular y enfermedades metabólicas (musculares, óseas, pulmonares y cerebrales). Objetivo: analizar a través de una revisión de la literatura los efectos del uso crónico de creatina sobre la función renal. Metodología: se trata de una revisión de la literatura argumentativa, basada en la técnica cuantitativa descriptiva-exploratoria. Las muestras investigadas provienen de revistas nacionales e internacionales, publicadas entre los años 2011 y 2021. Las revistas fueron adquiridas de las bases de datos electrónicas Scielo y PubMed. Resultados: varios estudios, en su mayoría realizados en hombres que realizaban entrenamiento de resistencia tres veces por semana, se suplementaron con monohidrato de creatina a diferentes concentraciones durante 7 días y se compararon con controles emparejados suplementados con dextrosol. Se realizaron varias pruebas, en algunas de ellas se recolectaron muestras de sangre y orina antes y 30 días después de la suplementación en las que se evaluaron numerosos parámetros bioquímicos y función renal. La suplementación con monohidrato de creatina no causó eventos adversos y, como se esperaba, promovió un aumento en el rendimiento y el peso corporal. Conclusiones: el presente estudio no encontró evidencia en la literatura que sustente que la creatina pueda representar un riesgo para la salud de hombres sanos. Sin embargo, los casos en la literatura sugieren que la creatina puede dañar la función renal con un uso indiscriminado, por lo que para no traer riesgos para la salud, se recomienda que las personas sanas que usen regularmente este suplemento no superen los $5 \mathrm{~g} / \mathrm{día}$.

Palabras clave: Creatina; Crecimiento del músculo esquelético; Alimentación suplementaria.

\section{Introdução}

O suplemento de creatina tem sido amplamente utilizado para melhorar o desempenho atlético. Além disso, recentes descobertas indicam que este suplemento tem um importante efeito terapêutico em muitas doenças caracterizadas por atrofia, fraqueza muscular e doenças metabólicas (músculos, ossos, pulmão e cérebro (Marese et al., 2019; Melo et al., 2016; Silva \& Linartevichi, 2021).

A creatina (ácido metilguanidinoacético) é um aminoácido que pode ser produzido endogenamente além de ser encontrado em certos alimentos, esse processo envolve órgãos como rins, pâncreas e fígado e usa outros aminoácidos (glicina, metionina e arginina) como substratos. A creatina existe nas formas livre (C) e fosforilada (CP), e 95\% de toda a creatina humana é armazenada no músculo esquelético. Quando a creatina é produzida pelo próprio corpo, ela passa por dois tipos processos: primeiro, o grupo amino da arginina se combina com o aminoácido glicina por meio da ação da glicina transaminase para formar o ácido guanidinoacético. Na segunda, a metiltransferase de guanidinoacetato de metila catalisa a metilação do grupo produzido pela primeira reação, ou seja, o grupo. O grupo metil em S-adenosilmetionina é adicionado ao grupo anterior para formar creatina (De Oliveira et al., 2018).

Pessoas que iniciam a manipulação da creatina com o propósito de melhorar o desempenho, rápido desenvolvimento muscular e encurtamento do tempo de recuperação, na maioria das vezes buscam benefícios por impulso, Sem prestar atenção aos suplementos e seus efeitos colaterais, alguns estudos mostraram que até 20 gramas de creatina por dia não são prejudiciais à saúde, entretanto, ainda não há evidências de que tenha segurança em longo prazo. Antes de iniciar a suplementação com creatina, é melhor buscar um professional porque você pode prejudicar sua saúde ou até mesmo o desempenho esportivo. Está cientificamente comprovado que quantidades excessivas de aminoácidos e proteínas aceleram a perda de função renal em pacientes que já tenham insuficiência renal crônica, portanto, o uso de creatina nesses pacientes é proibido (Oliveira et al., 2017).

A creatina é um produto da decomposição do pool de creatina, incluindo creatina livre e creatina fosfato. O pool é principalmente limitado ao músculo esquelético, que representa 95\% de toda a piscina de creatina e os 5\% restantes são órgãos, 
como rins e cérebro. Tanto a creatina quanto o fosfato de creatina ciclam espontaneamente em creatinina em um processo constante, irreversível e não enzimático com cerca de $1,1 \%$ da creatina do corpo e $2,6 \%$ do fosfato de creatina do corpo ciclando em creatinina. Esses estoques de creatina cíclicos são reabastecidos diariamente a partir da creatina da dieta proveniente da carne ou da síntese de novo usando um processo de duas etapas envolvendo o rim e o fígado (Feigenbaum et al.,2017).

Por muito tempo, acreditou-se que o aumento da massa magra obtida com a suplementação com creatina se devia à retenção de água causada pela creatina, mas alguns estudos mostraram que a proteína contrátil é afetada por mudanças no conteúdo de água intracelular. Uma explicação para o aumento da massa muscular é a diminuição da degradação que causa um aumento da síntese de proteínas. O edema celular causado pela retenção de água reduz a taxa de degradação de proteínas ao reduzir a liberação de aminoácidos de cadeia ramificada (leucina, valina, isoleucina) e retorna ao normal quando as células voltarem ao normal, indicando que a creatina diminui a proteólise muscular (Confortin et al., 2016).

Embora existam vários relatos sobre os efeitos nocivos da suplementação de creatina, incluindo cãibras, disfunções renais e hepáticas, hipertermia e desidratação, não existem evidências científicas que comprovem essas informações, talvez o único efeito adverso que a creatina causa seja a retenção hídrica, que possui algumas repercussões negativas sobre o desempenho físico, isso também vai depender da modalidade esportiva que a pessoa pratica. Não há nenhuma evidência específica na literatura de que a creatina possa ter quaisquer sinais de riscos à saúde ou efeitos colaterais óbvios para homens saudáveis (Stabile et al., 2017). O presente trabalho, teve como principal objetivo, analisar por meio de uma revisão da literatura os efeitos do uso crônico da creatina sobre a função renal.

\section{Metodologia}

Trata-se de uma revisão argumentativa da literatura, de base técnica quantitativa descritivo-exploratória (conforme caracterizado por Pereira et al., 2018). As amostras pesquisadas foram advindas de periódicos, nacionais e internacionais, publicados entre os anos de 2011 e 2021. Os periódicos foram adquiridos dos bancos de dados eletrônicos Scielo e PubMed. As palavras-chave utilizadas foram "creatinina" AND/OR "uso crônico" AND/OR "função renal". A pesquisa se utilizou da análise de conteúdo como técnica de instrumento de coleta de dados, seguida de uma pré-seleção de periódicos, nacionais e internacionais, sendo utilizados os seguintes critérios de inclusão aos mesmos: (1) conteúdos publicados entre os anos de 2011 e 2021, (2) bases textuais que detenham de entendimentos relacionados a, uso crônico da creatina e função renal, e (3) periódicos que seguiram indexados no banco de dados selecionado ou estivessem junto a esse disponíveis a pesquisa. Foram incluídos na pesquisa artigos com publicações a partir de 2011, a fim de ter informações mais atuais sobre o tema e trazer clareza sobre o tema proposto. Os critérios de exclusão foram: artigos data anterior a 2011 e que não trouxessem lucidez para o tema explorado. Apenas artigos publicados nos idiomas: português ou inglês foram considerados. Artigos com testes in vitro ou animal foram descartados. Os artigos pré-selecionados, após empregados os critérios para coleta de dados (conforme organizado por Minella \& Linartevichi, 2021), passaram por uma nova seleção, com base na leitura de seus resumos, sumários e prefácios, mantendo como fontes, somente, os que se mostraram mais fielmente adequados ao desenvolvimento pretendido.

\section{Resultados e Discussão}

A creatina foi descoberta pelo francês Michel Chevreu em 1835, quando ele relatou que um novo ingrediente orgânico foi extraído da carne. Justus Liebig em 1847, confirmou a existência da creatina como um componente regular da carne. O pesquisador destacou ainda que raposas selvagens que sobreviveram à caça têm 10 vezes mais creatina em sua carne do que raposas presas, sugerindo que o trabalho muscular pode levar ao acúmulo dessa substância (Faria, 2018). 
A função básica da creatina no corpo humano está diretamente ligada ao metabolismo energético, portanto, reservas corporais insuficientes podem limitar a função física, especialmente em atletas com formas explosivas de esportes, como levantamento de peso olímpico, futebol e basquete, ou aumentar a massa muscular como a musculação (Bouzas et al., 2015). Atualmente, a creatina existe na forma de monohidrato, micronizado, básico, etílico, fosfato e éster, e pode existir na forma de pós, géis, líquidos, barras. O fosfato de creatina é menos utilizado devido ao seu custo de produção ser mais elevado, mas ela tem o mesmo efeito sensibilizante na massa muscular (Oliveira et al, 2017).

A creatina pode ser encontrada em alimentos especialmente carnes e peixes. No entanto, é impraticável obter altas doses de creatina desses alimentos, cada 250 gramas de carne crua contêm apenas 1 grama de creatina, então a procura por esse suplemento é alta (Teixeira et al., 2020).

A Figura 1 mostra os inúmeros os fatores que a creatina influencia para a formação de massa muscular. A creatina funcionará de várias maneiras durante o processo de hipertrofia, começando com a inibição da miostatina, um fator que regula o crescimento muscular, que promove o ambiente de reforço muscular. A inibição da miostatina irá ativar as células satélites, o que promoverá o aumento de mionúcleos, aumentando a transcrição.

Figura 1 - Influência da creatina na hipertrofia muscular e mediadores moleculares envolvidos.

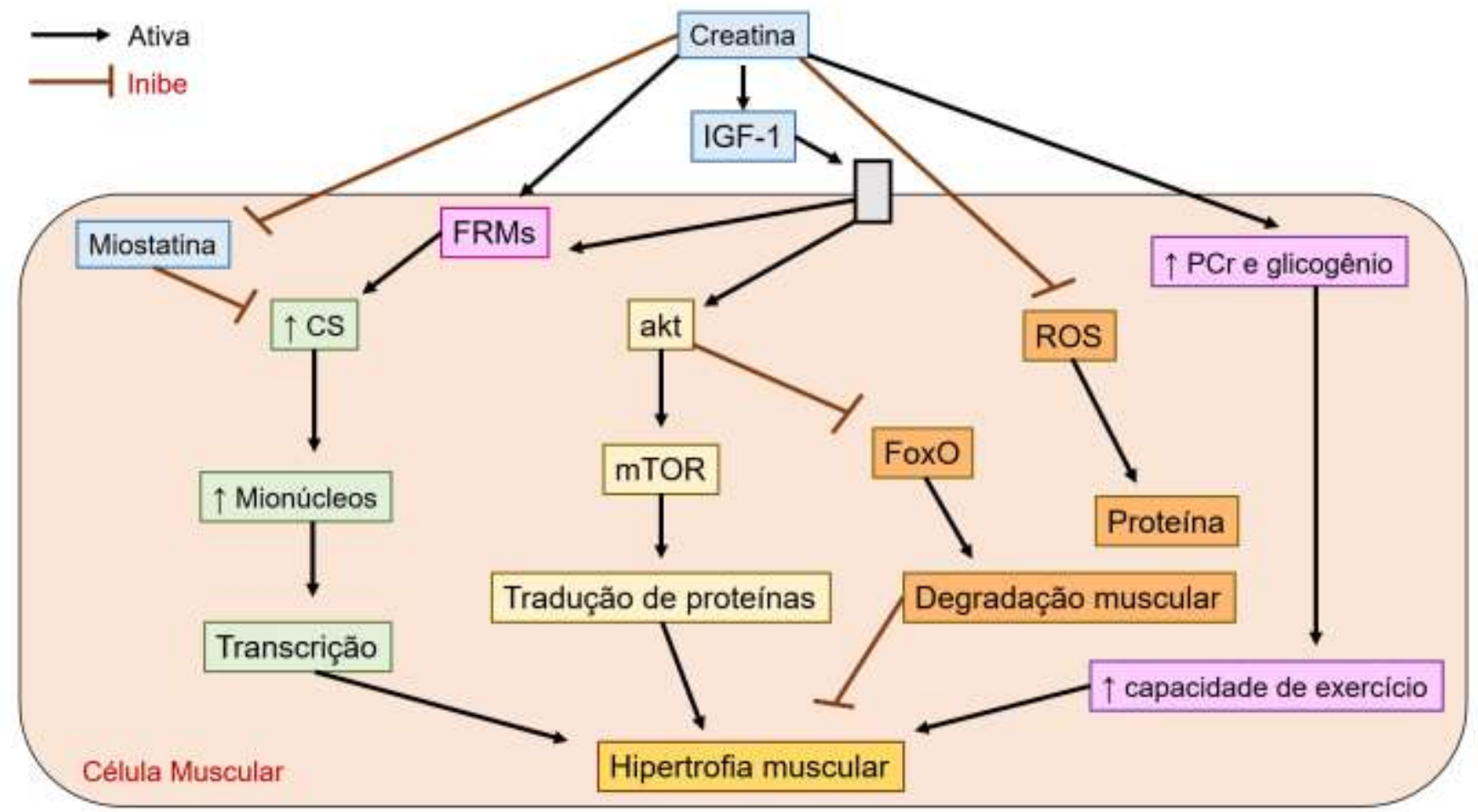

Abreviações: IGF-1(fator de crescimento semelhante à insulina); FRM (fator regulador miogênico); mTOR (alvo de rapamicina em mamíferos); PCr (fosfocreatina); RO (reativas ao O2); CS (células satélites); AKT (gene); FOX O3(gene responsável por proteólise muscular). Adaptado de Chilibeck et al. (2017).

A creatina ativará o fator regulatório miogênico (FRM) que estimulará as células satélites. Ela será também responsável conforme podemos observar na Figura 1 pelo aumento de fator de crescimento semelhante à insulina IGF-1 que estimulará a produção de FRM, também ativa o gene AKT que ativa o gene (alvo de rapamicina em mamíferos mTOR que é responsável pelo aumento da transdução proteica. Além disso o gene AKT, age inibindo o FOXO3 que é responsável pela proteólise muscular. Finalmente, o efeito mais conhecido da creatina que é o aumento de fosfocreatina PCR e glicogênio no músculo que permite a pessoa uma maior capacidade e força durante o exercício, que leva à hipertrofia (Chilibeck et al., 2017). 
Estudos têm mostrado que os suplemento de creatina deve ser usado em combinação com carboidratos simples, porque essa combinação vai aumentar o transporte da creatina para os músculos. Esse processo é mediado pela insulina, que estimula a enzima ATPase na bomba $\mathrm{Na}+/ \mathrm{K}+$, que por sua vez promove o transporte simultâneo de $\mathrm{Na}+/$ creatina (cada creatina possui duas moléculas de sódio) para manutenção ou recuperação gradiente normal de $\mathrm{Na}+\mathrm{e}$ potencial de membrana (Prestes et al., 2016).

Além disso, a suplementação da creatina ajuda a manter altos níveis de ATP durante a atividade física. Alguns autores acreditam que a suplementação da creatina pelos praticantes não tem efeito porque suas reservas estão cheias antes do uso, pois a absorção da creatina pelas fibras musculares é limitada, então o efeito ergogênico é ocorrido pelo aumento da concentração da creatina, quando seus estoques estão reduzidos (Santos et al., 2021b).

No início do século 20, vários estudos mostraram que nem toda a creatina que é ingerida é excretada na urina, levando à descoberta de que parte dela é armazenada pelo corpo. A partir disso, surgiram novas descobertas, como a influência da ingestão da Creatina sobre a composição muscular, conteúdo total no organismo humano e existência de outras formas deste composto, como, por exemplo, a fosfocreatina ( $\mathrm{PCr}$ ). Mais recentemente, estudos investigam sobre o seu potencial uso como recurso ergogênico (Assis et al., 2021; Bouzas et al., 2015).

Apesar de algumas alegações não comprovadas, as funções do fígado (enzimas, ureia) e rins (filtração de ureia glomerular e taxa de excreção de albumina) não tiveram nenhuma alteração significativa em pessoas saudáveis que suplementavam com creatina, mesmo durante vários meses e até anos, em populações jovens e idosas. Os efeitos potenciais (produção de aminas heterocíclicas) de mutagenicidade e carcinogenicidade que foram induzidas pela suplementação de creatina foram reivindicados pela Agência Sanitária Francesa (AFSSA), o que pode colocar os consumidores em risco. Mesmo que haja um ligeiro aumento (dentro da faixa normal) da excreção pela urina de metilamina e formaldeído após uma carga pesada de creatina ( $20 \mathrm{~g} / \mathrm{dia})$, isso não afeta a função renal. A busca pela excreção de aminas heterocíclicas ainda é uma tarefa no futuro, a fim de excluir claramente as reivindicações não comprovadas de certas instituições nacionais. Aconselhamos que a suplementação de creatina em altas doses (> 3-5 g / dia) não deve ser usada por indivíduos com doença renal preexistente ou aqueles com risco potencial de disfunção renal (diabetes, hipertensão, taxa de filtração glomerular reduzida (Kim et al., 2011).

A falta de provas bioquímicas sobre uma eventual perda da função renal em estudos controlados em humanos depende, pelo menos em parte, das dificuldades relacionadas à medição da taxa de filtração glomerular (TFG). Como a creatina é transformada em creatinina, a suplementação da creatina pode interferir na determinação do valor da creatinina e, consequentemente, superestimar o valor do clearance de creatinina, uma estimativa clássica da TFG. Para evitar o viés da interferência analítica pela creatinina secretada tubular, métodos padrão-ouro, como a depuração de inulina, devem ser usados. Com tudo, estudos em humanos são difíceis de realizar porque a inulina precisa ser injetada e o procedimento é demorado (Ferreira et al., 2015).

A creatina monohidratada é um dos poucos suplementos nutricionais para os quais as pesquisas têm demonstrado vários benefícios ergogênicos. Além disso, vários benefícios potenciais para a saúde foram relatados com a suplementação da creatina. As opiniões públicas e as políticas relacionadas à suplementação da creatina devem ser baseadas na avaliação cautelosa das evidências científicas dos ensaios clínicos bem controlados; não relatos anedóticos infundados, desinformação publicada na Internet e / ou pesquisas mal elaboradas que apenas divulgam mitos sobre a suplementação de creatina. Dados todas as vantagens bem conhecidas e perfis de segurança favoráveis de suplemento de creatina relatados na literatura científica e médica, é a visão do ISSN que legislaturas governamentais e organizações esportivas que restringem e / ou desencorajam o uso de creatina podem estar colocando os atletas em maior risco - particularmente em esportes de contato que apresentam risco de traumatismo craniano e / ou lesão neurológica, abrindo-se assim para responsabilidade. Isso inclui adolescentes e crianças 
atletas envolvidos em eventos esportivos que os colocam em risco de lesão na cabeça e / ou medula espinhal (Kreider et al., 2017).

O conteúdo de reservatório de creatina de um adulto de $70 \mathrm{~kg}$ é de aproximadamente $120-140 \mathrm{~g}$. A produção diária de fígado é de cerca de $2 \mathrm{~g}$ a ingestão diária com uma dieta normal de carne é de $1 \mathrm{~g}$. 95\% são encontrados nos músculos e o restante nos rins, fígado, cérebro e testículos. O CR armazenado no músculo é de $40 \%$ como CR e $60 \%$ como fosfocreatina. Diariamente entre 1 e 3\% do conteúdo total de creatina (ambas as formas) é transformado espontaneamente (sem participação enzimática) de forma constante e irreversível em creatinina (CRN), conforme figura 2, que passa para o sangue, é filtrado pelos glomérulos e excretado na urina. Uma proporção variável de CRN é secretada pelo túbulo proximal por meio da secreção de ânions orgânicos (Bouzas et al., 2015).

Figura 2 - Conversão reversível de creatina em fosfocreatina pelo fosfato inorgânico.<smiles>CN(CC(=O)O)C(=N)N(C)C(=O)O[18OH]</smiles>

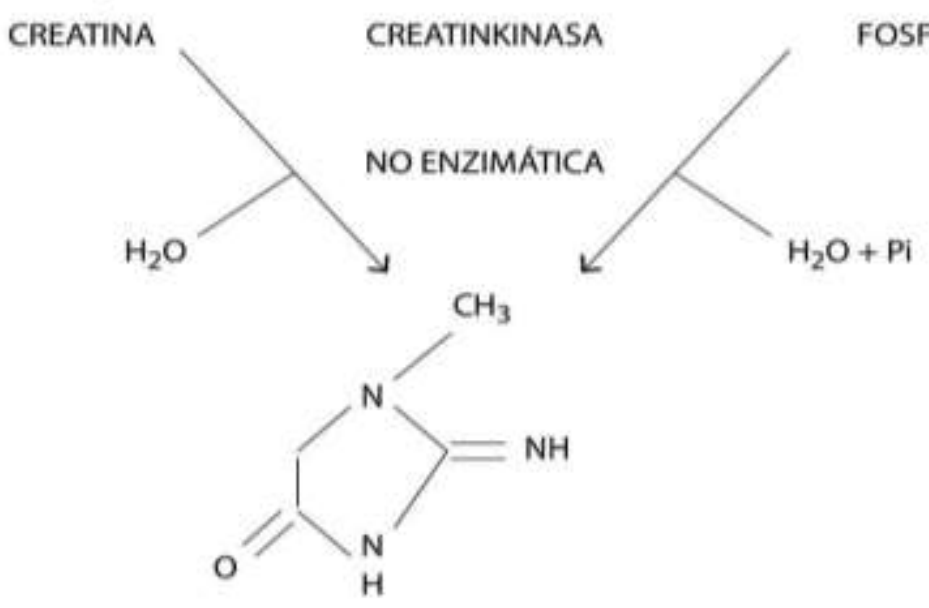

OSFOCREATINA

\section{CREATININA}

A conversão reversível de creatina em fosfocreatina pelo fosfato inorgânico por ação da enzima creatinase. A reação reversa produz ATP do ADP e creatinina como um produto residual, que é excretado na urina. $\mathrm{Pi}=$ fosfato inorgânico; $\mathrm{H}_{2} \mathrm{O}=$ água. Adaptado de Bouzas et al., 2015 .

Uma vez que doses supra fisiológicas de suplementação de creatina poderiam facilitar a demonstração de seu potencial para efeitos colaterais em nível de tecido, neste estudo usamos análises histopatológicas e enzimáticas para esclarecer o possível efeito protetor do exercício durante a suplementação de altas doses de Cr. Em geral, a doença renal é caracterizada por qualquer grau de dano morfológico e também por qualquer anomalia bioquímica, embora possa haver uma doença renal séria sem sinais clínicos ou mudanças laboratoriais que indicam insuficiência renal. Portanto, os níveis plasmáticos de ureia e creatinina são marcadores clássicos da função renal, pois representam um marcador simples de filtração glomerular (Teixeira et al., 2020).

O uso de suplementos nutricionais de creatina pode elevar temporariamente os níveis de creatinina sérica e simular a existência de uma nefropatia. Quando o uso de creatina está associado a uma dieta rica em proteínas, a elevação resultante do nitrogênio da ureia pode aumentar essa suspeita. Dada a prática atual dos laboratórios clínicos de relatar a taxa de filtração glomerular estimada, usando fórmulas que incluem creatinina, uma elevação da creatinina por essa causa pode levar a um 
sobre um diagnóstico de uma possível insuficiência renal crônica, com consequências importantes para pacientes e pacientes (Santos et al., 2021a).

Após a ciclagem, a creatinina deixa o tecido muscular para se difundir na corrente sanguínea e, finalmente, é filtrada através do glomérulo do rim para excreção. O processo de ciclagem não enzimática da creatina em creatinina é razoavelmente constante, de modo que a creatinina pode ser usada como um indicador da massa muscular existente. Por exemplo, um homem de $70 \mathrm{~kg}$ com $\sim 120 \mathrm{~g}$ de creatina corporal total produz cerca de $2 \mathrm{~g} /$ dia de creatinina a partir dessas reservas (Carvalho et al., 2011).

A creatina é frequentemente utilizada por pessoas que tem a pratica de exercícios físicos regularmente, fisiculturistas e por atletas profissionais como uma substância ergogênica. Seu uso se popularizou nas Olimpíadas de Barcelona em 1992 e é aceito como produto legal pela agência mundial antidoping. A suplementação da creatina tem mostrado vários benefícios como o aumento da massa muscular e seu conteúdo nos músculos, no desenvolvimento de maior potência e aumento de forças durante o exercício e menos fadiga durante os treinos. Os atletas que mais se beneficiam são aqueles que tem a pratica exercícios de alta performance e curta duração (por exemplo, corrida, salto). Desde que seu uso se tornou massivo entre os atletas (mais de 400 milhões de dólares em suplementos de RC são vendidos anualmente), foi sugerido que sua suplementação poderia ter efeitos deletérios sobre a função renal (Carvalho et al.,2011).

Um protocolo de $20 \mathrm{~g} / 7$ dias pode simular doença renal porque aumentará os níveis de creatinina sérica e portanto, mudará sua TFG (Taxa de Filtração Glomerular), que depende do valor da creatina sérica a ser calculada, resultando em danos aos rins. Isso porque, por não ser considerado um medicamento, o paciente não informará ao médico seu uso durante o exame. Nesta área, existem poucos estudos em pacientes que já apresentam doença renal, por isso é recomendado não usar este suplemento. Já que o armazenamento da creatina ocorre basicamente no início da suplementação, o excesso de creatina será excretado na urina nos dias seguintes, portanto, uma das possíveis reações adversas mais discutidas na comunidade científica é a suspeita de suplementação da creatina pode causar um estresse renal, no entanto, diversos estudos indicam que o uso agudo ou crônico em até 10 semanas deste composto até 30 gramas por dia não altera a função renal em pessoas saudáveis. Além disso, a suplementação diária de baixas doses (1,5 gramas) por até 5 anos não tem efeito sobre a função renal. Portanto, até o momento, não existem evidências científicas de que a suplementação da creatina prejudique a saúde de indivíduos saudáveis (Bouzas et al., 2015).

Em um estudo foi investigado os possíveis malefícios da suplementação da creatina em mulheres e homens, onde se utilizou de 26 parâmetros clínicos. Um estudo composto por 48 pessoas fisicamente ativos, em 7 grupos, com o objetivo de avaliar os protocolos de "saturação" de creatina (20g/ao dia durante 5 dias) e "manutenção" (3g ao dia ao durante 8 semanas). As pessoas que foram submetidas ao protocolo de "saturação" foram avaliadas após 1 dia e 6 semanas após o termino da suplementação. Já os indivíduos que foram submetidas ao protocolo de "manutenção" foram divididos em grupos que realizavam ou não treinamento de força.

Os pesquisadores acreditam que a suplementação com creatina não apresenta nenhum risco. No entanto, concentrações elevadas de creatinina e uréia foram registradas no grupo de suplementação de creatina por 5 dias e 8 semanas, respectivamente. Essas alterações foram interpretadas como de "baixa relevância clínica", citando primeiro as limitações da creatinina como marcador da taxa de filtração glomerular. Curiosamente, os pesquisadores só usaram os níveis plasmáticos de creatinina, potássio, sódio e ureia para avaliar a função renal. Embora esses métodos (a própria equipe de pesquisa) sejam geralmente reconhecidos como imprecisos, eles concluíram que a suplementação de creatina não afeta a função renal, não causa qualquer risco óbvio na função renal (de Oliveira et al., 2020).

Em um relato de um caso clinico, em que um paciente procura um hospital relatando de um edema na perna, ele tinha uma creatinina sérica de 2,2 $\mathrm{mg} / \mathrm{dl}$ e um eVFG de $33 \mathrm{ml} / \mathrm{min}$. Uma semana depois, sua creatinina sérica era de 2,56 $\mathrm{mg} / \mathrm{dl}$ e 
eVFG de $28 \mathrm{ml} /$ min. A avaliação por especialista não revelou outras alterações renais. O paciente relatou treinar 5 vezes por semana e ingerir 8 comprimidos diários de CR-EE (32 g) por 4 meses. Ele foi instruído a descontinuar os suplementos de CREE e 2 semanas depois seu CRN era 1,17 mg / dl e eVFG era $70 \mathrm{ml} / \mathrm{min}$. Concluiu-se que a ingestão de CR-EE foi responsável pelo aumento do CRN e pelo diagnóstico equivocado de insuficiência renal aguda (Williamson \& New, 2014).

Willis et al., (2011) relatam o caso de um homem que consultou por causa de um quadro viral prolongado e diagnosticou infecção por HIV. Sua função renal estava normal. Um mês após o início da terapia antirretroviral, seu CRN era de 1,88 mg / dl e eVFG (valor de filtração glomerular) era de $41 \mathrm{ml} / \mathrm{min}$. Suspeitou-se de a nefropatia estava relacionada ao HIV ou efeito colateral do medicamento. A avaliação renal estava normal. O paciente relatou que frequentava uma academia e consumia 24-30 g de suplemento proteico e 5-10 g de creatina monohidratada. Ele foi orientado a descontinuar os suplementos e o CRN diminuiu para 1,33 mg / dl e o eVFG aumentou para $61 \mathrm{ml} / \mathrm{min}$. Concluiu-se que os suplementos foram os responsáveis pela alteração.

Em um caso de um jovem de 18 anos, saudável, que iniciou um quadro de vômitos, náuseas e dor epigástrica após a ingestão de $20 \mathrm{~g}$ de Creatina durante 5 seguidos de $1 \mathrm{~g}$ por dia durante 6 semanas. Sua pressão arterial era $150 / 90 \mathrm{mmHg}$ e sua creatinina sérica era de 2,28 mg / dL, que subiu para 4,55 mg / dL durante a internação. A biópsia renal revelou necrose tubular aguda. Após suspensão do suplemento por 25 dias, a pressão arterial voltou ao normal e os indicadores de função renal voltaram aos valores anteriores ao suplemento. Este é o único caso de lesão renal aguda conhecida na literatura que ocorreu quando uma dose convencional de creatina foi suplementada em um paciente sem qualquer patologia prévia (Santos et al., 2021a).

Com o objetivo de avaliar os efeitos da suplementação nas funções, 35 homens saudáveis, foram divididos em três grupos (denominados de placebo, CRE1 e CRE2), durante um período de 8 semanas de treinamento especifico de musculação. Os grupos placebo e CRE1 fizeram o consumo de $0,03 \mathrm{~g} / \mathrm{Kg}$ de seus suplementos (maltodextrina e creatina, respectivamente), enquanto o grupo CRE2 fez o consumo de 5g/Kg. O grupo de controle (PLA) teve diminuição de 4,7\% da atividade renal, já nos grupos CRE1 e CRE2 foi observado aumento na atividade renal, porém, esses valores estiveram dentro dos limites de normalidades considerados de relevância clínica. Este estudo demonstrou que a suplementação da creatina em associação ao treinamento não altera a função renal, sendo assim totalmente segura para a sua suplementação (Carvalho et al., 2011).

Dezoito homens realizando treinamento de resistência três vezes por semana foram suplementados com creatina monohidratada $0,3 \mathrm{~g} / \mathrm{kg}$ por dia por 7 dias e comparados com controles pareados suplementados com dextrosol. Amostras de urina e sangue foram coletadas antes e 30 dias após a suplementação para avaliar 41 parâmetros bioquímicos e da sua função renal. A suplementação da creatina monohidratada não causou eventos adversos e, como esperado, promoveu aumento do desempenho e do peso corporal. Não foram encontradas nenhuma modificação dos parâmetros de glóbulos vermelhos, perfil de glóbulos brancos, perfil de lipídios do sangue, marcadores metabólicos e urinários, função hepática e renal foram observados no grupo suplementado (Almeida et al.,2020)

Um dos efeitos esperados dos suplementos orais de creatina é o crescimento da massa muscular. O peso corporal aumentou de $1,0 \%$ a 2,3\%, o que é atribuído à massa corporal magra e, mais especificamente, à massa muscular esquelética. Embora seja improvável que a retenção de água possa explicar completamente essas mudanças, nunca foi observado uma elevação na síntese de proteína muscular após suplementar com creatina. Evidências indiretas baseadas em análises de mRNA sugerem que a transcrição de certos genes é aumentada. Embora o efeito da creatina na síntese de proteína muscular pareça irrefutável de acordo com a publicidade, essa alegação permanece em debate na literatura científica. Os rins parecem manter sua funcionalidade em indivíduos saudáveis que suplementam com creatina, mesmo ao longo período (Antonio et al., 2021).

Não existem evidências na literatura que sustentem que a creatina pode representar um risco para a saúde de homens saudáveis, mas há muitos casos na literatura que mostram que a creatina possa prejudicar a função renal com o uso 
indiscriminado, para não trazer riscos à saúde, recomenda-se que indivíduos saudáveis que fazem uso regular desse suplemento não ultrapassem $5 \mathrm{~g}$ ao dia, pois não existem evidências científicas suficientes para garantir a ingestão segura acima dessa dose por muito tempo. É comum observar vários especialistas em saúde condenarem o consumo de creatina, especialmente com a afirmação de que esse suplemento é prejudicial à função renal. A dedução é simples e até mesmo lógica: a creatina é convertida espontaneamente a creatinina, a qual é excretada pelos rins. O excesso de creatina obtida pela suplementação geraria uma sobrecarga renal ao ser excretada, assim aumentando a creatinina, exame utilizado como marcador renal (Veira Junio et al., 2021; Falcão, 2016).

As alterações na função renal continuam sendo a principal preocupação entre os médicos. Há varias evidências conflitantes sobre se o consumo de creatina em usuários saudáveis tem efeito sobre os níveis de creatinina sérica ou urinária. Várias evidências sugerem que o efeito é mínimo em indivíduos saudáveis, com aumento reversível de aproximadamente 30\% da creatinina sérica e concomitante aumento da creatinina urinária, não tem evidencias que altera a taxa de filtração glomerular (Amaral \& Nascimento, 2020).

\section{Conclusão}

Diversos estudos, a maioria realizado em homens realizando treinamento resistido três vezes por semana foram suplementados com monohidrato de creatina em diferentes concentrações, por 7 dias e comparados com controles pareados suplementados com dextrosol. Vários testes foram realizados, em alguns deles, amostras de sangue e urina foram coletadas antes e 30 dias após a suplementação no qual inúmeros parâmetros bioquímicos e função renal foram avaliados. A suplementação de creatina monohidratada não causou eventos adversos e, como esperado, promoveu aumento do desempenho e do peso corporal. Conclusões: o presente estudo não encontrou na literatura, evidências que sustentem que a creatina pode representar um risco para a saúde de homens saudáveis. No entanto, casos na literatura sugerem que a creatina pode prejudicar a função renal com o uso indiscriminado, para não trazer riscos à saúde, recomenda-se que indivíduos saudáveis que fazem uso regular desse suplemento não ultrapassem $5 \mathrm{~g} /$ dia.

O farmacêutico tem como papel orientar esses pacientes ao uso correto da creatina, que se usado da maneira correta possui vários benefícios como citado acima. Pode também orientar a fazer a monitorização de exames laboratoriais para controle, orientar também ao possível efeito sobre a creatinina, que como citado a cima pode vir alterada causando um falso diagnostico de função renal, ao qual se acontecer, fazer as orientações corretas. Com base nessa revisão de literatura, sugere-se que, o uso de suplementos da creatina em indivíduos saudáveis por longos períodos é seguro para a saúde e não há evidências clínicas de que cause danos renais crônicos.

Novos estudos, sejam eles clínicos, ou revisões sistemáticas devem ser realizados para que outras populações sejam avaliadas e novos parâmetros sejam estudados, uma vez que, o uso indiscriminado da creatina é um fato e estudos que busquem traçar limites seguros para utilização da mesma devem ser estimulados.

\section{Referências}

Almeida, D., Colombini, A., \& Machado, M. (2020). Creatine supplementation improves performance, but is it safe? Double-blind placebo-controlled study. The Journal of sports medicine and physical fitness, 60(7), 1034-1039. https://doi.org/10.23736/S0022-4707.20.10437-7

Amaral, A. S. \& Ozanildo, V. N. (2020). Efeitos da suplementação de creatina sobre o desempenho humano: Uma revisão de literatura. BIUS -Boletim Informativo Unimotrisaúde em Sociogerontologia, 21 (15), 45-66. https://periodicos.ufam.edu.br/index.php/BIUS/article/view/8023

Antonio, J., Candow, D. G., Forbes, S. C., Gualano, B., Jagim, A. R., Kreider, R. B., Rawson, E. S., Smith-Ryan, A. E., VanDusseldorp, T. A., Willoughby, D. S., \& Ziegenfuss, T. N. (2021). Common questions and misconceptions about creatine supplementation: what does the scientific evidence really show? Journal of the International Society of Sports Nutrition, 18(1), 13. https://doi.org/10.1186/s12970-021-00412-w 
Assis, R. N., Souza, L. M. de, Soares, G. S. L., Cajueiro, J. F. de P., Souto, R. J. C., Afonso, J. A. B., \& Mendonça, C. L. de. (2021). Systemic implications of metallic foreign body syndrome in dairy cattle. Research, Society and Development, 10(11), e516101119469. https://doi.org/10.33448/rsd-v10i11.19469

Bouzas, J. C. M., Leite, M. S. R., Silva, F. M., Sousa, S. C. (2015). Creatina: estratégia ergogênica no meio esportivo: uma breve revisão. Revista de Atenção à Saúde, 13 (43), 52-60. https://doi.org/10.13037/rbcs.vol13n43.2539

Brito, T. N. S., Oliveira, A. R. A., Silva, A. K. C. (2015). Taxa de filtração glomerular estimada em adultos: características e limitações das equações utilizadas. Revista Brasileira de Análises Clínicas, 48 (1), 360-366.

Carvalho, A. P. P. F., Molina, G. E., Fontana K. E. (2011). Suplementação com creatina associada ao treinamento resistido não altera as funções renal e hepática. Revista Brasileira de Medicina do Esporte, 17 (4), 237-241. https://doi.org/10.1590/S1517-86922011000400004

Chilibeck, P. D., Kaviani, M., Candow, D. G., \& Zello, G. A. (2017). Effect of creatine supplementation during resistance training on lean tissue mass and muscular strength in older adults: a meta-analysis. Open access journal of sports medicine, 8, 213-226. https://doi.org/10.2147/OAJSM.S123529

Confortin, F. G., De Sá, C. A., Wildner, P. P. (2016). Avaliação da creatina associada à dextrose como suplemento nutricional ergogênica sobre a performance de atletas de futebol. Revista Brasileira de Nutrição Esportiva, 10 (56), 136-144. http://www.rbne.com.br/index.php/rbne/article/view/614

De Oliveira, M. V., De França, E., Dias, I. R., Xavier, A. P., Yoshioka, C. A., Hirota, V. B., Caperuto, E. C. (2018). Suplementação com creatina e treinamento de força: uma análise comparativa do tempo de ação de dois protocolos de utilização e seus efeitos na força, massa muscular e composição corporal. Revista Mackenzie de Educação Física e Esporte, 15(2), 22-45.

De Oliveira Vilar Neto, J., da Silva, C. A., Meneses, G. C., Pinto, D. V., Brito, L. C., da Cruz Fonseca, S. G., de Sousa Alves, R., Martins, A., de Oliveira Assumpção, C., \& De Francesco Daher, E. (2020). Novel renal biomarkers show that creatine supplementation is safe: a double-blind, placebo-controlled randomized clinical trial. Toxicology research, 9(3), 263-270. https://doi.org/10.1093/toxres/tfaa028

Falcão, L. E. M. (2016). Saturação de creatina em indivíduos fisicamente ativos: Técnica eficaz ou desnecessária. Revista Brasileira De Nutrição Esportiva, 10(57), 327-334. http://www.rbne.com.br/index.php/rbne/article/view/642

Faria, D. P. B. (2018). Suplementação de creatina no ganho de força e hipertrofia muscular em praticantes de treinamento de força: uma bre ve revisão narrativa. Revista Eletrônica Acervo Saúde. 13, 1476-1483. http://doi.org/10.25248/REAS274_2018

Feigenbaum J., Hunt K., Hoffman R. (2017). Dietary creatine supplements raise serum creatinine mimicking acute kidney injury. The Aasgaard Company, 4 (5), 2-10.

Ferreira, L. G., Bergamaschi, C. T., Lazaretti-C, M., Heilberg, I. (2015). Efeitos da suplementação de ratos de creatina na composição corporal e função renal, Medicine \& Science in Sports \& Exercise, 37 (9), 1525- 1529. https://doi.org/10.1590/S1517-86922007000500004

Kim, H. J., Kim, C. K., Carpentier, A. et al. (2011). Studies on the safety of creatine supplementation. Amino Acids, 40, 1409-1418. https://doi.org/10.1007/s00726-011-0878-2

Kreider, R. B., Kalman, D. S., Antonio, J., Ziegenfuss, T. N., Wildman, R., Collins, R., Candow, D. G., Kleiner, S. M., Almada, A. L., \& Lopez, H. L. (2017). International Society of Sports Nutrition position stand: safety and efficacy of creatine supplementation in exercise, sport, and medicine. Journal of the International Society of Sports Nutrition, 14, 18. https://doi.org/10.1186/s12970-017-0173-Z

Marese, A., Ficagna, E., Parizotto, R., \& Linartevichi, V. (2019). Principais mecanismos que correlacionam a microbiota intestinal com a patogênese da depressão. Fag Journal of Health, 1(3), 232-239. https://doi.org/10.35984/fjh.v1i2.40

Melo, A. L., De Araújo, V. C., \& Reis, W. A. (2016). Efeito da suplementação de creatina no treinamento neuromuscular e composição corporal em jovens e idosos. Revista Brasileira De Nutrição Esportiva, 10(55), 79-86. Recuperado de http://www.rbne.com.br/index.php/rbne/article/view/612

Minella, F. C. O., \& Linartevichi, V. F. (2021). Efeitos do canabidiol nos sinais e comorbidades do transtorno do espectro autista. Research, Society and Development, 10(10), e64101018607. https://doi.org/10.33448/rsd-v10i10.18607

Oliveira, L., Azevedo, M., \& Cardoso, C. (2017). Efeitos da suplementação de creatina sobre a composição corporal de praticantes de exercícios físicos. Revista Brasileira de Nutrição Esportiva, 11 (61), 10-15. http://www.rbne.com.br/index.php/rbne/article/view/618

Pereira A. S. et al. (2018). Metodologia da pesquisa científica. UFSM.

Prestes, J., Foschini, D., Marchetti, P., Charro, M., Tibana, R. (2016). Prescrição e periodização do treinamento de força em academias. (2a ed.), Editora Manole.

Santos, G. de O., Cruvinel, P. B. N. F., Pereira, M. B. L., Silva, D. N. da., Santos, L. L. dos, Souza, R. B. de, \& Silva, S. L. (2021a). The Effects of Creatine Supplementation in Resistance Trainers - A Literature Review. Research, Society and Development, 10(9), e46410918263. https://doi.org/10.33448/rsdv10i9.18263

Santos, J. P. C., Martins, G. H. da S, \& Ferreira, J. C. de S. (2021b). The use of creatine in strength training and improving physical performance. Research, Society and Development, 10(11), e59101119410. https://doi.org/10.33448/rsd-v10i11.19410

Silva, K., \& Linartevichi, V. (2021). Deficiência androgênica do envelhecimento masculino e a reposição de testosterona. Fag Journal of Health, 3(1), 84-89. https://doi.org/10.35984/fjh.v3i1.306

Stábile, L., Da Silva, F. A., Oliveira, L. C. N., Bernardo, D. N. A. (2017). A utilização da suplementação de creatina no treinamento de força. Revista Odontológica de Araçatuba, 38 (1) 14-18. https://apcdaracatuba.com.br/revista/2017/04/TRABALHO2.pdf 
Research, Society and Development, v. 10, n. 14, e89101421867, 2021

(CC BY 4.0) | ISSN 2525-3409 | DOI: http://dx.doi.org/10.33448/rsd-v10i14.21867

Teixeira, Y., Almeida, P. T., Pereira, T. C., Barreto, J. A. P. S., Menezes, R. S. M. de, Silva, C. L., Bezerra, P. de S., Sousa, L. de N., Silva, P. N. da, Sousa, S. M. de, Lima Júnior, J. C. C. de, Oliveira, H. D. M. de, Oliveira, P. L. de, Silva, E. B. da, Bellas, J. M. de A., Pereira, D. F., Furtado, Y. R. A. L., Oliveira, A. H. de, Andrade, A. O., Landim, H. S., Lima, A. E. T., Macedo, L. R. de, \& Canuto, A. F. A. (2020). Effects of Creatine Supplementation on Physical Performance: Na integrative literature review. Research, Society and Development, 9(7), e982974947. https://doi.org/10.33448/rsd-v9i7.4947

Vieira Júnior, M. da C., Cambraia, R. P., \& Pereira Júnior, A. do C. (2021). Consumption of dietary supplements by physical activity participants in gyms. Research, Society and Development, 10(10), e374101018877. https://doi.org/10.33448/rsd-v10i10.18877

Williamson, L., \& New, D. (2014). How the use of creatine supplements can elevate serum creatinine in the absence of underlying kidney pathology. BMJ case reports, 2014, bcr2014204754. https://doi.org/10.1136/bcr-2014-204754

Willis, J., Jones, R., Nwokolo, N., \& Levy, J. (2010). Protein and creatine supplements and misdiagnosis of kidney disease. BMJ (Clinical research ed.), 340, b5027. https://doi.org/10.1136/bmj.b5027 